\title{
PREVENTING A COLLAPSE OF THE WEST ANTARCTIC ICE SHEET: CIVIL ENGINEERING ON A CONTINENTAL SCALE
}

(Abstract only)

\author{
by \\ D. R. MacAyeal \\ (Geophysical Fluid Dynamics Program, Box 308, Princeton University, Princeton, \\ New Jersey 08540, U.S.A.)
}

\begin{abstract}
A collapse of the West Antarctic ice sheet due to warming by atmospheric carbon dioxide is a potential threat to mankind because low-lying land would be flooded by rising sea-level. Intervention would be possible by creating one or several artifical ice rises on the floating ice shelves surrounding the West Antarctic ice sheet. Ice rises are places where the ice shelf has run aground locally on the sea bed. Existing ice rises obstruct ice flow and are responsible for maintaining the ice sheet in its present
\end{abstract}

stable condition. An artificial ice rise could be created by (1) drilling a hole through the ice shelf in a choice position such as over a sea-bed ridge, (2) pumping large volumes of sea-water from beneath the ice shelf so as to flood the surface, and (3) continuing to pump until the frozen sea-water has thickened the ice shelf by $100 \mathrm{~m}$ over an area of $100 \mathrm{~km}^{2}$. Approximately $1.6 \times 10^{6} \mathrm{~kW}$ of power would be required to accomplish the task in ten years. This would cost approximately $20 \times 10^{9}$ US dollars.

\section{MODELLING OF ICE ACCRETION ON WIRES}

\section{(Abstract only)}

by

\author{
Lasse Makkonen
}

(Päivätie 7c, Espoo, 02210 Finland)

\begin{abstract}
A tilie-dependent numerical model of ice accretion is used to simulate the growth of ice loads on wires. Both dry growth (rime) and wet growth (glaze) are modelled in order to examine the dependence of the growth rate of ice load on atmospheric conditions.

The results show that during dry growth under constant atmospheric conditions the growth rate of an ice load slightly decreases. In conditions of wet growth, however, the growth rate increases until the process turns to dry growth after reaching the critical deposit diameter. The effect of air temperature on the growth rate in dry growth turns out to be
\end{abstract}

rather small. However, the final ice load after longterm rime formation is temperature-dependent, because the limiting deposit diameter, at which the collection efficiency becomes practically zero, is reached at different ice masses depending on the ice density. The modelled relationships between the growth rate of ice load and the atmospheric variables are compared with observational data and with proposed formulae for the calculation of the intensity of wire icing. The possibilities of estimating the formation of ice loads for practical purposes with a simple method, using the routinely measured meteorological parameters only, are discussed. 